\title{
E-Learning \& Environmental Policy: The case of a politico-administrative GIS
}

\author{
N.D. Hasanagas, A.D. Styliadis, E.I. Papadopoulou, L.A. Sechidis
}

\author{
Nikolaos D. Hasanagas, Athanasios D. Styliadis, Lazaros A. Sechidis \\ Kavala Institute of Technology, Department of Landscape Architecture \\ City of Drama, Greece, GR 66100 \\ Email: styliadis@ath.forthnet.gr, nikolaos.hasanagas@gmail.com, \\ lazikas@photo.topo.auth.gr

\section{Eleni I. Papadopoulou} \\ Aristotle University of Thessaloniki, Faculty of Agricultural Science \\ Department of Agricultural Economics, City of Thessaloniki, GR 54124 \\ E-mail epapa@agro.auth.gr
}

\begin{abstract}
Is an effective knowledge exchange and cooperation between academic community and practitioners possible? Implementation of e-learning in specialized policy fields pertains to the most challenging priorities of ICTs and software engineering. In multidisciplinary academic areas which combine environmental policy studies with positivist subjects (like environmental issues, forest policy, rural development, Landscape Architecture etc), the using of e-learning system in analyzing policy issues steadily gains in importance and is a method which connects the academic community and the researchers with the practitioners and field experts. Such initiatives incorporate a number of politometrics- relevant algorithms embedded in a context of political geography (i.e. visualized hierarchies in different regionrelated policy issues). This is the case addressed in this paper. The GIS learning management system introduced in this paper is based on certain criteria concerning organizational models and region-specific politico-administrative hierarchies. Scenarios of politico-administrative metadata achieving optimal power synergy are extracted through a sequencing technique, combining vector-algebra software and statistics and can be used for both teaching and research purposes.
\end{abstract}

Keywords: e-Learning, GIS, politometrics, forest policy, environmental issues, rural development policy, socio-informatics.

\section{Introduction}

Although the political structures of the "western" and "civilized" world are considered to be standardized in the framework of a single "cosmopolite" value system, the power structures in environmental policy issues are quite different between regions. Not in every region of Europe the state actors necessarily concentrate the same degree of power. Sometimes private enterprises, environmental or economic groups are the leading actors. An actor (e.g. environmental or landowner interest group) should also be adjusted to the particular condition of regional policy networks in order to succeed. Socio-informatics software like VISONE (network analysis) is based on elaborated vector-algebra algorithms [3] which are aiming at quantifying and visualizing the intangible political relations [1] and informal dynamics of environmental policy and in general of rural development policy. The application of such a computer-aided "political geometry" methodology with region-specific cases is the "cornerstone" of structuring a GIS functional for politometrics and thus of implementing a GIS Learning Managament System (GLMS) [4] in the context of a post-modern political geography depicting regional-specific (in)formal hierarchies (Archimedes findings).

The implementation of e-learning in specialized policy fields pertains to the most challenging priorities of ICTs and software engineering. In multidisciplinary academic areas which combine environmental policy studies with positivist subjects (like Landscape Architecture, Rural Sociology and Economics, Forest Science etc), the using of e-learning system in analyzing policy issues steadily gains in importance (Archimedes findings). Moreover, in cross-sectoral policy networks such as those which are developed on forest policy issues and are discussed in this paper, it is impossible to separate policy sectors; Environmental issues, rural development policy and forest policy 
are an inseparable part of what is called "integrated rural development". Such networks involve not only forest owner and industrial interests but also other groups (e.g. agricultural museums, environmental NGOs, agrarian associations etc). Not only the classical rural territory but also urban-related interests are involved. Thereby, a new urban-countryside relation is developed. Thus, a policy-relevant filtering of learning objects is necessary in order to enable the exchange of knowledge between academic community (or researchers) and practitioners/ field experts.

The e-learning system suggested in this paper is expected to be appropriate for achieving not only an effective over-bridging between academic community and practitioners in forest policy and in the wider environmental and rural development issues but also an effective organisation and coordination of means of forest and rural resource management, an acceptable evaluation of forest resources and acceptable procedures of estimating or accounting the economic, material and non-material values of forest, frictionless goal-setting and decision-making involving private and public actors, and a method of examining issues of ambiguity and law-making concerning forest and wider natural resources. As long as this e-learning is implemented among target groups from different policy sectors related to forestry (e.g. spatial planning, agriculture, tourism, water management etc), a minimization of conflicts is feasible [6]. This holistic approach of policy-making is enabled through the complete analysis of policy networks, which is an operational form of system theory $[8,10]$. In other words, a new systemic analysis of classical forest policy is the basis of this e-learning system.

An adaptive process that selects learning objects (region-specific policy structures and actors) from a digital repository and sequences them in a way which is appropriate for the targeted GIS learning community or individuals $[2,6,11,13,16,17]$, is also necessary for reducing computational time and gaining in objectivity and acceptance of politico-administrative conclusions. Such a method is also required as the rural development issues are characterized by complex and unpredictable informal procedures and there are no clear and common indicators for evaluating rural development policy in Europe (RUDI findings). Nevertheless, a qualitative and participative evaluation is necessary on the part of learners (students specialized in Forest Policy, Rural Sociology and Economics, Development and spatial engineering, lobbyists of interest groups etc). Many types of intelligent learning systems are available but without GIS functionality. In the GLMS proposed in this paper, five key components could be identified, which are common in most GIS systems: region-specific data acquisition, algebraic and statistical analysis, processing data of actors and regional networks, construction of political geography database, and calculating/ visualizing formal and informal hierarchies. Figure 1 depicts the interactions between these five GIS components $[4,18]$.

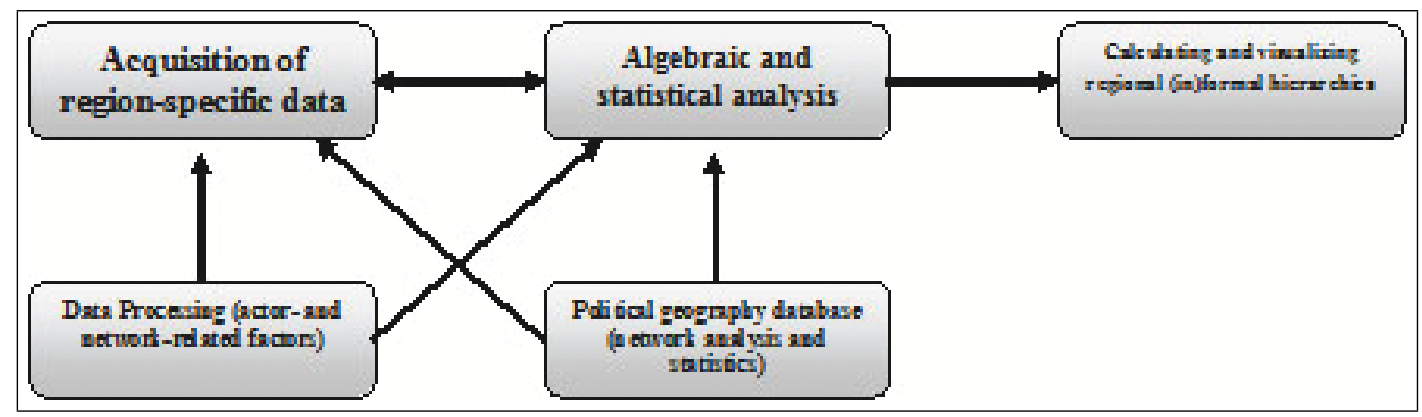

Figure 1: The main components of an intelligent GLMS.

The selection of learning content (in this case, the region-specific formal and informal hierarchies) is based on policy-research criteria depending on complex and heterogeneous cognitive styles [3,8,15] which may be characterized as "region-" and "administrative-based" (Archimedes findings). In this way, a wide range of learner expectations is satisfied $[9,10,12]$. Particularly, the administrative-based elements (organisational theories) are much more subjective than the regional ones. Therefore, cooperation between multidisciplinary academic and field experts (e.g. environmental, forest and agricultural scientists, public administrators, lobbyists, sociologists, informatics experts etc) is necessary in order to achieve acceptance and integrated analysis of real cases. Such a criteria set constitutes a decision support system (DSS) for learners [4] and teaching staff which enables both of them to reduce hypothetical options and produce original and accurate research results and constitutes a basic component of an intelligent GLMS [16,19]. Although many digital DSS types have been proposed, these are applicable only to examination of human-building interaction and perceptual relations $[10,17,18,22,23,25]$ and they are not combined with GLMS. Other DSS types which are combined with GLMS [16,24] are strictly related to 
spatial elements and not to region-specific politico-administrative issues (Archimedes findings). In this paper, the development of a politico-administrative GIS is addressed. A region- and administrative-based filtering process of learning objects is discussed. Politico-administrative metadata are proposed which can be used for learning object filtering on the basis of the Open GIS Consortium guidelines (standards) concerning GIS functionality [4, 20].

\section{Digitalizing the "political geometry" in a region-specific GIS}

The formal and informal hierarchy shaped in every region surveyed is composed of three power dimensions, as shown in formula (1) [21]:

$$
\text { Politico-administrative Power }=\text { Trust }+ \text { Incentives }+ \text { Uniqueness }
$$

Trust is used for leading even when surveillance is infeasible, provision of incentives is for assuring commitment, and uniqueness is useful for exerting institutional pressure. According to the RUDI findings, informal hierarchies are more decisive for the policy output than the formal ones because of the lack of detailed criteria of decision-making and evaluation in rural development policy. Trust is a relational value based on expertise, experience and personality and is accumulated through successive transfer of reputation. If e.g. the Forestry Commission trusts the Royal Scottish Forestry Society, which trusts the National Trust of Scotland and the last two actors trust the Friends of the Loch Lomond, then the last one proves to be the most trustworthy as it is able to gain the trust of all previous actors (also of the Forestry Commission indirectly). For the reputation of the actor A, it is not merely important how many actors trust A, but also how much reputation these actors gain from other actors etc. These actors can be ordered on the vertical and horizontal axis of a matrix. Thereby the network can be algebraically processed. Formula (2) which is known as Katz-status formula is applied for calculating the power status of an actor in a network:

$$
T=(I-a C)^{-1}-I
$$

where $\mathrm{T}$ is a matrix including the status values of all actors as elements, $\mathrm{C}$ is the matrix presenting the real network of trust, and a is a dumping factor. The same formula is applied in the case of the provision of incentives and uniqueness dependence relations. This algorithm is used by VISONE software.

VISONE layers vertically the actors (learning objects) according to their power status measured in \% (Figure 2). The horizontal order has no politico-administrative meaning. It is obvious that in the simple polygon form, the policy networks are not disclosing any hierarchies developed in their regions. When they are layered, they acquire a pyramid-shape form. The sharper the pyramid (vertical length in relation to horizontal length), the higher the oligarchy, as defined in formula (3) [14,21]:

$$
\text { Oligarchy }=\frac{\text { Status max }- \text { Status min }}{\text { Status Average }}
$$

The sharpest pyramid is this of UK1 issue network (oligarchy=2,40), while the "pyramid" of Greek network does not seem to be a pyramid at all, as the oligarchy is quite low $(1,48)$. In Figure 2, the power status of each actor can be examined by the learners in relation to its orientation (use or conservation of natural resources) and its legal character (private or state actor). In this way, learning effects and original conclusions with academic and practical value can be made by the learners through the interpretation of this digital visualization of region-specific hierarchies with abstract but applicable politico-administrative metadata $[1,13,20]$.

An output of such a GIS produced by the comparative analysis of these digital pyramids of (in)formal regional hierarchies is concisely presented in Figure 3: The power status can be examined by the learners again in relation to the legal character and to the orientation among various regions. Thereby, policy-relevant conclusions can be made regarding the winning possibility, considering these determinants (legal character and orientation).

E.g. in the Greek and Spanish regions, the private actors are much more powerful than the state ones, with noticeable difference in comparison with the European average. The inverse hierarchy can be recognized in the case of the UK1 and UK2 networks (Scotland). The conservation-oriented actors (e.g. environmental NGOs and agencies) are more powerful than the use-oriented ones in Denmark. This is a case subversive to the average power relation. The science-oriented actors (universities, research institutes) are more powerful than the other actors in the network of Finland and in one region-specific network in Spain. These results can be further interpreted by using qualitative information about the content of the policy issues (RUDI and Archimedes findings). 


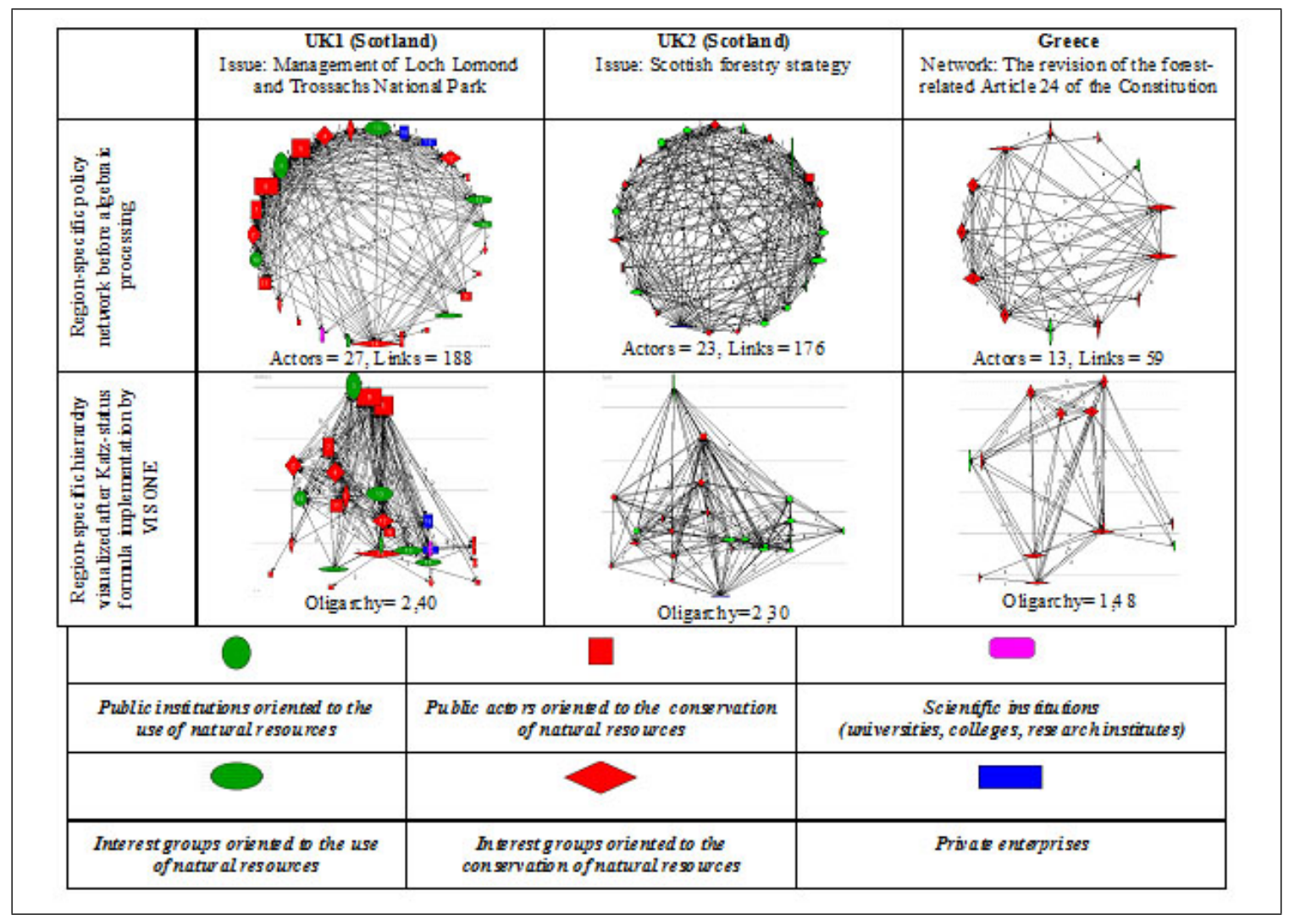

Figure 2: Region-specific networks of politico-administrative power.

A further elaboration of DSS $[2,5,16]$ for the diagnosis of favorable (or unfavorable) participation in a regionspecific network $[9,19]$ is possible by applying stepwise regression to this political-geographic database: Not every actor can participate in every regional network with equal chance of developing power. According to the New-Institutionalist approach the power $(\mathrm{P})$ achieved by an actor does not depends only on the organizational $(\mathrm{O})$ features of this actor but also on the regional network $(\mathrm{N})$ conditions in which this actor is involved, as shown in the Figure 4. Which combinations of actor and regional network features lead to the optimal power? One can deduce hypotheses on the O-factors and induce the $\mathrm{N}$-factors through stepwise regression [21]. In Figure 5, the procedure of the stepwise regression works as a filtering process, reduces the power-ineffective combinations and produces ideal types of politico-administrative metadata (actor- and regional network-related power determinants). An ideal type, for instance, is the following one:

An actor (e.g. an environmental NGO) with multidisciplinary team (0,284*MULTIDIS), which is not radical $(-0,261 *$ RADICALI), and has no state representatives at its board $(-0,203 *$ STATECH $)$, can develop optimal power in a network which is composed of only a few actors $\left(-0,427^{*}\right.$ ACTORS), provides many opportunities of lobbying $(0,394 *$ POTLOBB $)$, is characterized by low relative importance of state $(-0,296 *$ RELIMPST), and involves only a few policy sectors $(-0,243 *$ INTERSEC).

Comparing these actor- and network specific factors with GIS outputs such as these which are described in Figure 3, it is concluded, for instance, that this type of actor described in Figure 5, has optimal chance to develop power in the regional networks of Bavaria.

O-factors were selected by using specific organisational theories (i.e. contingency model which is expressed by the absence of state representative at the board and the using of alternative expertise for surviving in heterogeneous regional- political environments). The regional $\mathrm{N}$-factors were inductively selected by the stepwise regression. The combinations of $\mathrm{O}$ - and $\mathrm{N}$-factors can also be characterized as regional-specific critical scenario analysis [2,5,7,21].

According to RUDI results, the deviation between formal and informal hierarchies and the differences between regional networks can be attributed to the inflexible bureaucracy, the complexity, the centralisation and to the lack of formal and clear criteria of decision-making and evaluation in Greece and in other European countries. Furthermore, the challenges posed by the requirement of harmonizing social, economic and environmental standards 


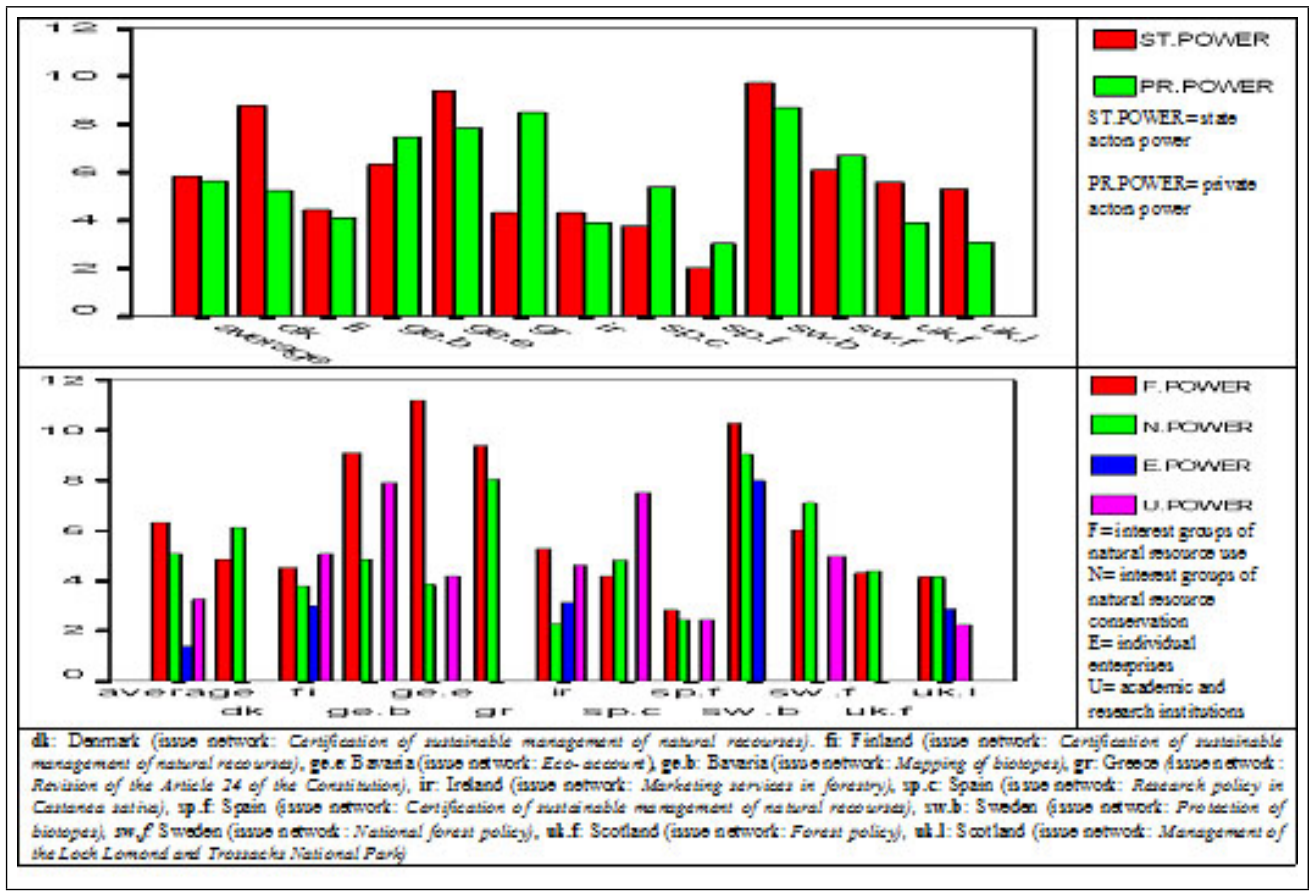

Figure 3: Politometrics-embedded GIS.

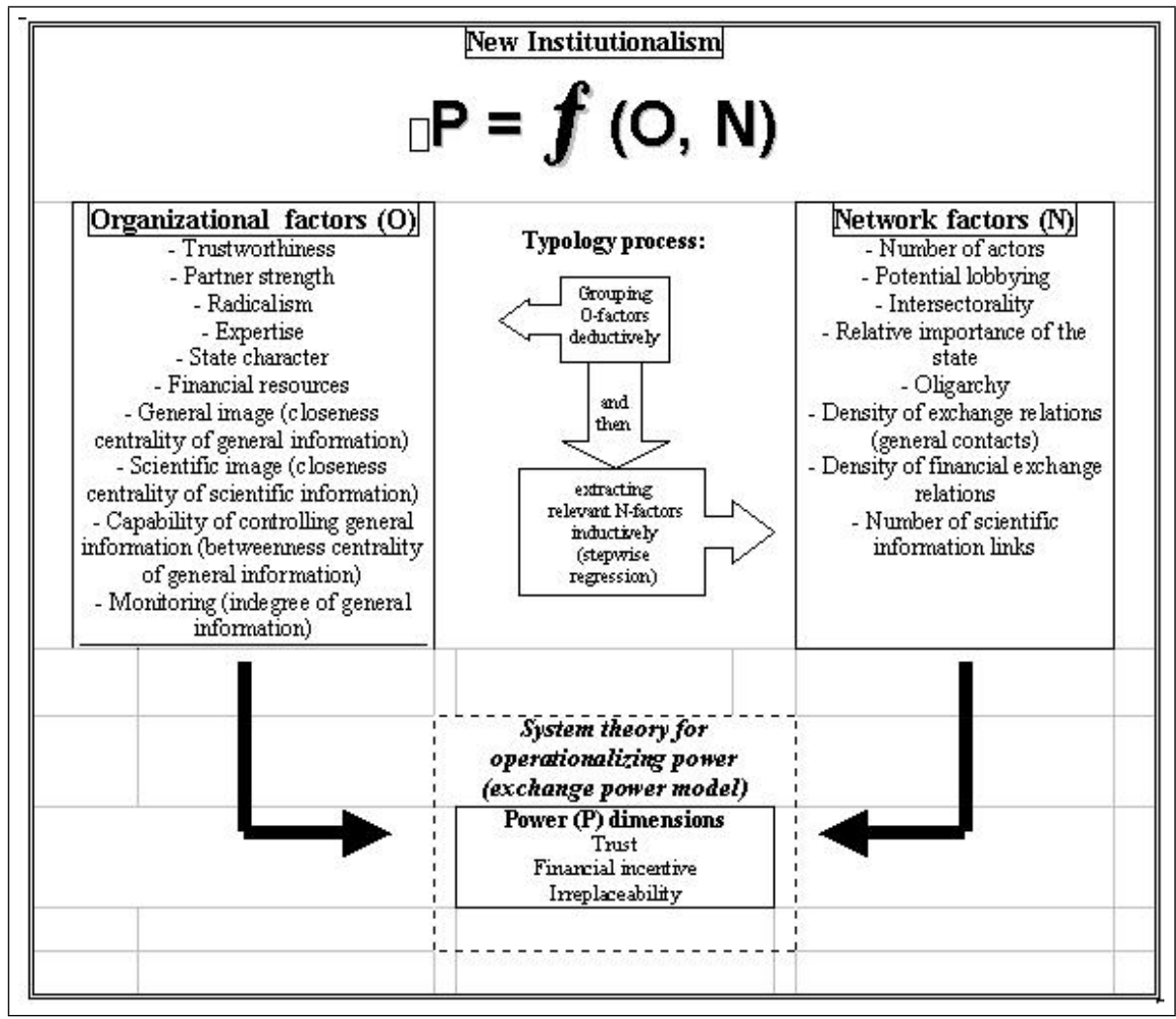

Figure 4: Optimal power synergy through politico-administrative meta-data: actor-related and regionspecific power determinants. 


\begin{tabular}{|c|c|c|c|c|c|}
\hline \multicolumn{6}{|c|}{ Dependent Variable: POWER } \\
\hline Modell & & \multicolumn{2}{|c|}{ Untandardised coefficients } & \multirow{2}{*}{$\begin{array}{l}\begin{array}{l}\text { Standardised } \\
\text { coefficients }\end{array} \\
\text { Beta }\end{array}$} & \multirow{2}{*}{ Significance } \\
\hline$\overline{1}^{-}$ & (Constant) & $--\frac{\mathrm{B}}{10,762}$ & Standard enor & & \\
\hline 1 & ACTORS &,- 230 & 040 &,$- 5 n$ & 30001 \\
\hline \multirow[t]{3}{*}{$\overline{2}$} & (Constant) & $\overline{79} 69^{-}$ & $\overline{1}, \overline{0} 6 \overline{4}$ & & $\overline{0} 0 \overline{0}$ \\
\hline & ACTORS & -200 &, 036 &,- 457 & 000 \\
\hline & POTLOBB & 109 & 024 &, 381 & 000 \\
\hline \multirow[t]{4}{*}{$\mid$\begin{tabular}{|l}
3 \\
\end{tabular}} & (Constant) & 6,647 & 1,151 & & 800 \\
\hline & ACTOKS & $-1,198$ & 035 &,- 452 & 000 \\
\hline & POTLOBB &, 113 &, 023 &, 395 & 000 \\
\hline & MULTIDIS &, 354 &, 137 &, 206 &, 011 \\
\hline \multirow[t]{5}{*}{4} & (Constant) & 8,311 & 1,279 & & 000 \\
\hline & ACTORS & -219 & 0,035 & -502 & 000 \\
\hline & POTLOBB &, 111 &, 022 & 387 & ${ }_{3}^{0} 000$ \\
\hline & MULTIDIS &, 357 &, 132 & .208 & ,008 \\
\hline & RELTHPST &,- 704 & .367 & -3208 &, 010 \\
\hline \multirow[t]{6}{*}{5} & (Coustant) & 11,702 & 1,727 & & 000 \\
\hline & ACTORS & -237 &, 034 &,- 58 & 000 \\
\hline & POTLOBB &, 098 &, 032 & 342 &, 000 \\
\hline & MULTIDIS &, 401 & 128 & .233 &, 002 \\
\hline & RETLIMPST & -799 & 259 & -236 & 0093 \\
\hline & RADICALI & $-1,979$ & .707 & -316 & .006 \\
\hline \multirow[t]{7}{*}{6} & (Constant) & 13,390 & 1,757 & & ,000 \\
\hline & ACTORS &,- 241 & ,033 &,- 52 &, 000 \\
\hline & POTLOBB & ,103 & ,021 &, 362 & ,000 \\
\hline & MULTIDIS & ,410 & , 123 &, 238 & ,001 \\
\hline & REILHPST &,- 764 & ,249 &,- 226 & , 0003 \\
\hline & RADICALI & $-2,574$ & ,709 &,- 281 & ,000 \\
\hline & STATECH &,- 627 & ,218 &,- 216 &, 005 \\
\hline
\end{tabular}

Figure 5: Stepwise regression on politometrical GIS data. 
complicate the policy-making.

\section{Summary and Conclusions}

The main goal of vector-algebra software (i.e. VISONE) is the digitalization and visualization of the formal and informal politico-administrative hierarchies of region-specific issue networks. The goal of the stepwise regression as a filtering process is the reduction of the searching space. GIS learning object repositories often contain numerous possible combinations of regional hierarchy features and actor-related characteristics. Without visual complete network analysis and statistical techniques like the stepwise regression, the examination of and familiarization with all possible learning objects would be characterized by conceptual complexity and time-consumption. This would be discouraging for the learners, especially if they were practitioners (e.g. lobbyists of environmental and industrial groups, or employees of forest services and agricultural directorates) and not only normal students. The method presented in this paper is a system for filtering learning objects which is based on knowledge domains $[7,11,19]$ (i.e. organisational theories and practical experience) and seems to be appropriate for student and adult education as well.

\section{Acknowledgements}

The research initiative proposed by this paper has been supported by the EU-funded "Archimedes" Research Project (Department of Landscape Architecture, Kavala Institute of Technology, Drama, Greece), by the EUfunded research project

"RUDI: Rural Development Impacts- Assessing the impact of Rural Development policies, incl. LEADER" Consortium no: 213034, 7th Framework Programme for Research and Technological Development, (Department of Agricultural Economics, Faculty of Agricultural Science, Aristotle University of Thessaloniki, Greece), and by the Institute of Forest Policy and Nature Conservation of Goettingen University (Germany).

\section{Bibliography}

[1] M. A. Rajan, M. Girish Chandra, L.C. Reddy, P. Hiremath, Concepts of Graph Theory Relevant to Ad-hoc Networks. Int. J. of Computers, Communications \& Control, 3, Suppl. issue: Proceedings of ICCCC, 465-469, 2008.

[2] M. Medjoudj, P. Yim, Extraction of Critical Scenarios in a Railway Level Crossing Control System. Int. J. of Computers, Communications and Control, 2(3), 252-268, 2007.

[3] A. Anohina, M. Vilkelis, R. Lukasenko, Incremental Improvement of the Evaluation Algorithm in the Concept Map Based Knowledge Assessment System. Int. J. of Computers, Communications \& Control, 4(1), 6-16, 2009.

[4] A.D. Styliadis, I.D. Karamitsos, D.I. Zachariou, Personalized e-Learning Implementation - The GIS Case. International Journal of Computers, Communications \& Control, 1(1), 59-67, 2006

[5] P. Dolog, N. Henze, W. Nejdl \& M. Sintek, Personalization in Distributed eLearning Environments. Proc. of the 13th International World Wide Web Conference, New York, USA, 2004.

[6] M. Krott, N.D. Hasanagas, Measuring bridges between sectors: Causative evaluation of cross-sectorality. Forest Policy and Economics, 8(5), 555-563, 2006.

[7] M. Stanojevic, M. Vujosevic, B. Stanojevic, Number of Efficient Points in some Multiobjective Combinatorial Optimization Problems. Int. J. of Computers, Communications \& Control, 3, Suppl. issue: Proceedings of ICCCC, 497-502, 2008.

[8] Y. Birot, G. Buttoud, R. Flies, K. Hogl, M. Pregernig, R. Päivinen, I. Tikkanen, M. Krott Voicing interests and concerns: institutional framework and agencies for forest policy research in Europe. Forest Policy and Economics, 4(4), 333-350, 2002.

[9] N. Magnani, L. Struffi, Translation sociology and social capital in rural development initiatives. A case study from the Italian Alps. Journal of Rural Studies, 25(2), 231-238, 2009.

[10] J. Murdoch, Networks - a new paradigm of rural development?. Journal of Rural Studies, 16(4), 407-419, 2000. 
[11] G. McCalla,The Fragmentation of Culture, Learning, Teaching and Technology: Implications for the Artificial Intelligence in Education Research Agenda in 2010. International Journal of Artificial Intelligence in Education, 11, 177-196, 2000.

[12] LSAL, SCORM Best Practices Guide for Content Developers, 2003. Cernegie Mellon Learning Systems Architecture Lab. Retrieved in September 2005 from the World Wide Web: http://www.lsal.cmu.edu/lsal/expertise/projects/developersguide

[13] Kinshuk, R. Oppermann, A. Patel \& A. Kashihara, Multiple Representation Approach in Multimedia based Intelligent Educational Systems. Artificial Intelligence in Education Journal, Amsterdam: IOS Press. 259-266, 1999.

[14] A. Real T., N.D. Hasanagas, Complete Network Analysis in Research of Organized Interests and Policy Analysis: Indicators, Methodological Aspects and Challenges. Connections, 26(2), 89-106, 2005.

[15] P.R. Polsani, Use and Abuse of Reusable Learning Objects. Journal of Digital information, (2003). Retrieved in September 2005 from the World Wide Web: http://jodi.ecs.soton.ac.uk/Articles/v03/ i04/Polsani.

[16] A.D. Styliadis, E-Learning Documentation of Historical Living Systems with 3-D Modeling Functionality. INFORMATICA, 18(3), 419-446, 2007.

[17] A.D. Styliadis, P.G. Patias, N.C. Zestas, 3-D Computer Modeling with Intra-Component, Geometric, Quality and Topological Constraints. INFORMATICA, 14(3), 375-392, 2003.

[18] A.D. Styliadis, M.Gr. Vassilakopoulos, A spatio-temporal geometry-based model for digital documentation of historical living systems. Information \& Management, 42, 349-359, 2005.

[19] I.J. Terluin, Differences in economic development in rural regions of advanced countries: an overview and critical analysis of theories. Journal of Rural Studies, 19(3), 327-344, 2003.

[20] M. S. Urban \& E. G. Barriocanal, On the Integration of IEEE-LOM Metadata Instances and Ontologies. Learning Technology Newsletter, 5(1), 2003.

[21] N.D. Hasanagas, Power factor typology through organisational and network analysis. Usinhg environmental policy networks as an illustration. Ibidem. Stuttgart. 2004.

[22] A.D. Styliadis, Digital documentation of historical buildings with 3-d modeling functionality. Automation in Construction, 16, 498-510, 2007.

[23] A.D. Styliadis, Historical photography-based computer-aided architectural design: Demolished buildings information modeling with reverse engineering functionality. Automation in Construction, 18, 51-69, 2008.

[24] A.D. Styliadis, I.I. Akbaylar, D.A. Papadopoulou, N.D. Hasanagas, S.A. Roussa, L.A. Sexidis, Metadatabased heritage sites modeling with e-learning functionality. Journal of Cultural Heritage, 10, 296-312, 2009.

[25] A.D. Styliadis, D.G. Konstantinidou, K.A. Tyxola, ECAD System Design - Applications in Architecture. Int. J. of Computers, Communications \& Control, 3(2), 204-214, 2008.

Nikolaos D. Hasanagas Born in 1974. Assistant Professor in environment-related subjects at the Kavala Institute of Technology, Drama, Greece. BSc and MSc eq. in Environmental Sciences (Aristotle Univ. of Thessaloniki, Greece), BA and MA eq. in Social Sciences, PhD in Environmental Policy Analysis (Goettingen Univ., Germany).

Athanasios D. Styliadis Born in 1956. Professor of digital architecture and design computing at the Department of Landscape Architecture at the Kavala Institute of Technology, Drama, Greece. Diploma in Surveying Engineering, MSc in Computer Science (Dundee Univ., Scotland), PhD in CAAD and GIS (Aristotle Univ. of Thessaloniki, Greece).

Eleni I. Papadopoulou Born in 1957. Assistant Professor in Rural Policy at the Faculty of Agricultural Science at the Aristotle University of Thessaloniki, Greece. BSc in Agriculture Engineering, MSc in Agricultural Economics (Univ. of Reading, UK), PhD (Aristotle University of Thessaloniki).

Lazaros A. Sechidis Born in 1968. Assistant Professor in Geodesy at the Department of Landscape Architecture at the Kavala Institute of Technology, Drama, Greece. Dipl. in Surveying Engineering, PhD in Photogrammetry (Aristotle Univ. of Thessaloniki). 